\title{
Detection of Mutations Associated with Isoniazid Resistance in Mycobacterium tuberculosis Isolates from China
}

\author{
Min Zhang, ${ }^{1}$ Jun Yue, ${ }^{2}$ Yan-ping Yang, ${ }^{1}$ Hong-mei Zhang, ${ }^{1}$ Jian-qiang Lei, ${ }^{1}$ Rui-liang Jin, ${ }^{1}$ \\ Xue-lian Zhang, ${ }^{1}$ and Hong-hai Wang ${ }^{1 *}$ \\ State Key Laboratory of Genetic Engineering, Institute of Genetics, School of Life Science, Fudan University, ${ }^{1}$ \\ and Shanghai Pneumology Hospital, ${ }^{2}$ Shanghai 200433, People's Republic of China
}

Received 11 May 2005/Returned for modification 16 June 2005/Accepted 15 August 2005

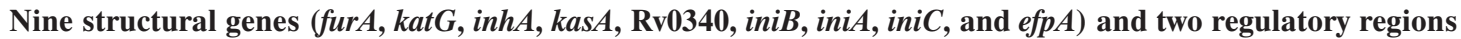
(the oxyR-ahpC intergenic region and the promoter of mabA-inhA) in 87 isoniazid (INH)-monoresistant and 50 INH-susceptible Mycobacterium tuberculosis isolates collected from five provinces of China were analyzed by sequencing. Eighty-two (94.3\%) INH-resistant isolates had mutations in the katG gene, with the katG Ser315Thr mutation predominant (55.2\%). No mutation at codon 463 of $k a t G$ was detected among the 50 INH-susceptible isolates with different IS6110 fingerprints. In addition, there were $35(40.2 \%)$ INH-resistant isolates that had a mutation at codon 463 of $k a t G$. Of the INH-resistant strains, $20(23.0 \%)$ isolates harbored double mutations at two separate loci of katG. Mutations in the inhA promoter region occurred in 13 (14.9\%) isolates; $4.6 \%$ of the isolates had $i n h A$ structural gene mutations, and $11.5 \%$ harbored mutations in the oxyR-ahpC intergenic region. Drug resistance-associated mutations were detected in the iniBAC region and efp $A$.
\end{abstract}

Tuberculosis (TB) represents one of the world's greatest sources of mortality and morbidity, with approximately 8 million new infections and 2.5 million to 3 million deaths per year. China has one of the highest burdens of TB in the world, with the second-largest total number of TB cases globally (9, 34, 41). Currently, throughout the world, isoniazid (INH) and rifampin (RIF) together represent the backbone of short-course chemotherapy treatment for Mycobacterium tuberculosis infections. The rise of multidrug-resistant tuberculosis (MDR-TB), defined as TB showing resistance to at least INH and RIF, is a serious threat to TB control. The World Health Organization estimates that 50 million people worldwide are infected with MDR-TB. The highest percentages of MDR-TB cases that are newly contracted have been found in China (11\%) and eastern Europe ( 7 to $14 \%)(5,10,11)$.

RIF resistance appears to be mediated by mutations of the $\beta$ subunit of RNA polymerase, which is encoded by the $r p o B$ gene. Previous work indicates that more than $95 \%$ of RIFresistant strains are associated with mutations within an 81-bp region of the $r p o B$ gene. Specific mutations, insertions, and deletions have been detected, and this 81-bp region has been termed the rifampin resistance determinant region $(7,13,42)$. In contrast, INH resistance is apparently controlled by a more complex genetic system that involves several genes $(15,31)$. INH, a first-line antituberculosis drug, has a simple chemical structure consisting of a pyridine ring and a hydrazide group. INH is a prodrug that enters actively growing tubercle bacilli by passive diffusion (4). The bifunctional bacterial enzyme catalase-peroxidase (KatG) converts INH to a range of oxygenated and organic toxic radicals that attack multiple targets

\footnotetext{
* Corresponding author. Mailing address: Institute of Genetics, Fudan University, 220 Handan Rd., Shanghai 200433, People's Republic of China. Phone: 8621 65643777. Fax: 8621 65648376. E-mail: hhwang@fudan.edu.cn.
}

in the mycobacterial cell $(32,33)$. The best-characterized target of these radicals is the cell wall mycolic acid, but DNA, carbohydrates, lipids, and DNA metabolism may be targeted as well (6). Reports suggest that an NADH-dependent enoyl acyl carrier protein reductase, encoded by $\operatorname{inh} A$, and a $\beta$-ketoacyl acyl carrier protein synthase, encoded by $\operatorname{kas} A$, are involved in the biosynthesis of mycolic acids and are two potential intracellular enzymatic targets for activated INH $(23,25)$. Resistance-associated amino acid substitutions have been identified in kat $G$, inh $A$, and kasA of INH-resistant isolates of M. tuberculosis $(31,33)$. The overexpression of InhA due to an upregulation mutation in the promoter region of $i n h A$ (preceding the $m a b A$-inh $A$ operon) also produces INH resistance via a titration mechanism (29). Mutations in the $\operatorname{oxy} R$ - $a h p C$ intergenic region, where the putative promoter of $a h p C$ is located, are considered to be a compensatory mechanism for the loss of KatG function in resistant strains $(16,38)$. In addition, mutations in other genes, including fur $A$, ini $A$, iniB, and iniC, were associated with INH resistance but in much lower percentages of strains (31).

A convergence of data indicates that INH-resistant clinical isolates of $M$. tuberculosis from diverse geographic regions have distinct mutation frequencies in the genes kat $G, k a s A$, and $\operatorname{inh} A$ (regulatory and structural regions) and the $\operatorname{oxy} R$ $\operatorname{ahpC}$ intergenic region $(6,15,16,18,23,28,31,37)$. Few of these findings have been applied to studies of Chinese isolates. Therefore, the present study investigated the mutations associated with INH resistance in $M$. tuberculosis isolates from China. As recent findings indicate that fur $A$ and the iniBAC (ini $A$, iniB, and ini $C$ ) region are also related to INH resistance and that the single nucleotide polymorphisms in efp $A$ were detected in both INH-resistant and -susceptible isolates (31), we characterized the mutations in these genes by DNA sequencing. 
TABLE 1. $k a t G$ double mutations in 87 INH-resistant $M$. tuberculosis isolates from China

\begin{tabular}{|c|c|c|c|c|c|c|}
\hline \multirow{2}{*}{$\begin{array}{l}\text { Nucleotide no. for the } \\
\text { first mutation in katG }\end{array}$} & \multirow{2}{*}{ Amino acid } & \multicolumn{2}{|l|}{ Second mutation in katG } & \multirow{2}{*}{$\begin{array}{l}\text { No. }(\%) \text { of } \\
\text { isolates with } \\
\text { mutation }\end{array}$} & \multirow{2}{*}{$\begin{array}{c}\text { INH MIC } \\
\text { range } \\
(\mu \mathrm{g} / \mathrm{ml})\end{array}$} & \multirow{2}{*}{$\begin{array}{l}\text { Additional mutation(s) } \\
\quad \text { (no. of isolates) }\end{array}$} \\
\hline & & Nucleotide no. & Amino acid & & & \\
\hline $\mathrm{G} \rightarrow \mathrm{C}$ at position 944 & Ser315Thr & $\mathrm{G} \rightarrow \mathrm{T}$ at position 1388 & Arg463Leu & $13(14.9)$ & $1->256$ & $\begin{array}{l}\text { oxyR-ahpC (2), inhA } \\
\quad \text { promoter (2), iniA (1) }\end{array}$ \\
\hline $\mathrm{G} \rightarrow \mathrm{A}$ at position 944 & Ser315Asn & $\mathrm{G} \rightarrow \mathrm{T}$ at position 1388 & Arg463Leu & $1(1.1)$ & 16 & None \\
\hline $\mathrm{G} \rightarrow \mathrm{C}$ at position 944 & Ser315Thr & $\mathrm{G} \rightarrow \mathrm{C}$ at position 2053 & Gly685Arg & $1(1.1)$ & 2 & None \\
\hline $\mathrm{G} \rightarrow \mathrm{C}$ at position 944 & Ser315Thr & A insertion at position 1329 & Frameshift & $1(1.1)$ & 64 & oxyR-ahpC (1) \\
\hline $\mathrm{G} \rightarrow \mathrm{T}$ at position 1388 & Arg463Leu & $\mathrm{G} \rightarrow \mathrm{T}$ at position 1471 & Gly491Cys & $2(2.3)$ & $4-8$ & $\operatorname{inh} A(1)$ \\
\hline $\mathrm{G} \rightarrow \mathrm{T}$ at position 1388 & Arg463Leu & $\mathrm{CG} \rightarrow \mathrm{TA}$ at position $1543 \rightarrow 1544$ & Arg515Tyr & $1(1.1)$ & 8 & None \\
\hline $\mathrm{G} \rightarrow \mathrm{T}$ at position 1388 & Arg463Leu & 64-bp insertion at position 1559 & & $1(1.1)$ & $>256$ & oxyR-ahpC (1), efpA (1) \\
\hline
\end{tabular}

\section{MATERIALS AND METHODS}

Clinical M. tuberculosis isolates and susceptibility testing. In total, $87 \mathrm{INH}-$ monoresistant and $50 \mathrm{INH}$-susceptible $M$. tuberculosis isolates were recovered from 137 patients (age range, 16 to 88 years; 71 were male and 66 were female) from five provinces of eastern China (Jiangsu, Zhejiang, Anhui, Fujian, and Jiangxi). Lowenstein-Jensen medium was used for the cultivation of the isolates, and all isolates were initially classified as INH monoresistant or susceptible by use of a BACTEC MGIT 960 instrument (Becton Dickinson, Microbiology Systems, Sparks, MD) and standard procedures with the following critical concentrations: INH, $0.1 \mu \mathrm{g} / \mathrm{ml}$; RIF, $1 \mu \mathrm{g} / \mathrm{ml}$; streptomycin, $1 \mu \mathrm{g} / \mathrm{ml}$; and ethambutol, $5 \mu \mathrm{g} / \mathrm{ml}$. The MICs were determined by the E test and the proportion method (31). The conventional antibiotic susceptibility testing by the proportion method was performed at the respective institutions (Shanghai Pneumology Hospital and Shanghai CDC TB Laboratory). The E test and the proportion method produced results in good overall agreement.

IS6110-based RFLP. All isolates were assessed for their genetic relatedness by IS6110 restriction fragment length polymorphism (RFLP). PvuI-digested DNA of M. tuberculosis was probed with the insertion element IS6110 according to the standardized method of van Embden et al. $(19,37)$.

Sequencing strategy. The nine structural genes (fur $A, \operatorname{kat} G, \operatorname{inh} A, \operatorname{kas} A$, Rv0340, iniBAC, and efp $A$ ) and two regulatory regions (the oxyR-ahpC intergenic region and the promoter of $m a b A$-inh $A$ ) analyzed for a single nucleotide polymorphism were sequenced, after amplification by PCR using KOD polymerase (Toyobo, Co.), with high fidelity according to the manufacturer's instructions. The oligonucleotide primers and PCR conditions have been described previously (31). After purification (QIAquick column PCR purification kit; QIAGEN), the PCR product was sequenced by using an ABI 377 automated DNA sequencer (Applied Biosystems, Inc.). The isolates that showed new nonsynonymous mutations were sequenced again by cloning the PCR products into the T vector. Sequence data were assembled and analyzed by CLUSTAL W.

Nucleotide sequence accession numbers. The sequences with novel mutations were deposited in GenBank under accession numbers DQ056349 to DQ056361.

\section{RESULTS}

Among the 137 M. tuberculosis isolates examined, 87 were monoresistant to INH. DNA fingerprinting was carried out to distinguish whether the mutations occurred separately in the two populations or whether they happened in one population and then spread to the other region. The IS6110 RFLP assay of the 137 isolates revealed that the number of hybridizing bands ranged from 8 to 21. Except for two isolates that shared the same print pattern, all other isolates had unique fingerprints. Some isolates with the same mutation had different IS6110 patterns, a result indicating epidemiologic independence. Two isolates with similar IS6110 fingerprints had different mutations in katG. A total of $56(64.4 \%)$ of the 87 INH-resistant isolates and $34(68 \%)$ of the $50 \mathrm{INH}$-susceptible isolates had an IS6110-based banding pattern characteristic of the Beijing genotype of $M$. tuberculosis.

The DNA sequence of the $k a t G$ gene was determined for 50 INH-susceptible $M$. tuberculosis isolates and 87 INH-resistant isolates. All INH-susceptible isolates possessed the wild-type sequence, whereas resistance-associated mutations within the $k a t G$ gene were found in $82(94.3 \%)$ of the 87 INH-resistant isolates. Mutations at codon 315 occurred in 56 (64.4\%) isolates, with a base substitution at nucleotide 944 predominating $(\mathrm{Ser} \rightarrow \mathrm{Thr}[\mathrm{AGC} \rightarrow \mathrm{ACC}], 48$ isolates $[58.5 \%$ of the $82 \mathrm{~kat} G$ mutants]). Other substitution mutations occurred at codon 315 $(\mathrm{Ser} \rightarrow \mathrm{Asn}$ [AGC $\rightarrow \mathrm{AAC}], n=5 ; \mathrm{Ser} \rightarrow$ Gly $[\mathrm{AGC} \rightarrow \mathrm{GGC}] ; n$ $=1$; Ser $\rightarrow$ Arg $\quad[\mathrm{AGC} \rightarrow \mathrm{AGG}] ; n=1$; and $\mathrm{Ser} \rightarrow$ Ile [AGC $\rightarrow$ ATC]; $n=1$ ). All of the $50 \mathrm{INH}$-susceptible isolates had different IS6110 fingerprints, indicating their epidemiologic independence. No mutation at codon 463 of $\mathrm{katG}$ was detected in the $50 \mathrm{INH}$-susceptible isolates. In contrast, 35 $(40.2 \%)$ of the INH-resistant isolates were found to harbor the Arg463Leu mutation. A characteristic finding was the presence of double mutations occurring at two separate loci of katG. Among the $82 \mathrm{~kat} G$ mutants, 20 (24.4\%) isolates had double mutations in the katG region (Table 1), with Ser315 plus Arg463 double mutations predominating (14 isolates).

Other drug resistance-associated mutations were detected in the katG gene (Table 2). Two isolates had complete katG deletions, based on the reproducible absence of PCR product; one isolate had termination mutations at codon 90 (TGG $\rightarrow$ TAG). Except for a single base insertion (insertion of $\mathrm{T}$ and $\mathrm{A}$ at nucleotide positions 1311 and 1329, respectively) and deletion (deletion of $\mathrm{G}$ at position 1559), a 64-bp fragment insertion at position 1559 was detected in only one isolate, in which mutations at other loci occurred, such as the $\operatorname{ahpC}$ promoter region and efp $A$. The 64-bp insertion sequence was TGCAGCCACAAGTCGGGTGGGAGGTCAACGACCCC GACGGGGATCTGCGCAAGGTCATTCGCAC. Other substitution mutations of $k a t G$ occurred at codons 491 (Gly $\rightarrow$ Cys $[\mathrm{GGC} \rightarrow \mathrm{TGC}] ; n=2), 685(\mathrm{Gly} \rightarrow \mathrm{Arg}$ [GGC $\rightarrow \mathrm{CGC}] ; n=1)$, and $515(\mathrm{Arg} \rightarrow \mathrm{Tyr}[\mathrm{CGC} \rightarrow \mathrm{TAC}] ; n=1)$.

Of the $82 \mathrm{~kat} G$ mutants, $53(64.6 \%)$ had no additional mutations in other genes, whereas $29(35.4 \%)$ had changes in other genes, some of which have not been previously reported (Table 3). A total of 10 isolates (12.2\%) had additional mutations in the inhA regulatory region, $4(4.9 \%)$ had additional mutations in the inh $A$ structure gene, 10 (12.2\%) had additional mutations in the oxyR-ahpC intergenic region, $4(4.9 \%)$ had additional mutations in $k a s A, 6(7.3 \%)$ had additional mutations in the ini region ( $\mathrm{Rv} 0340$ and iniBAC), and $1(1.2 \%)$ had additional mutations in efp $A$. $k a t G$ is cotranscribed with fur $A$ from a common regulatory region, and reports suggest that fur $A$ is a negative regulator of $\operatorname{katG}(28,43)$. An INH- 
TABLE 2. Nonsynonymous mutations in INH-susceptible and -resistant M. tuberculosis from China

\begin{tabular}{|c|c|c|c|c|c|}
\hline \multirow{2}{*}{$\begin{array}{l}\text { Gene or gene } \\
\text { region }\end{array}$} & \multirow{2}{*}{$\begin{array}{l}\text { Nonsynonymous } \\
\text { mutation }\end{array}$} & \multirow{2}{*}{$\begin{array}{l}\text { No. of INH- } \\
\text { susceptible } \\
\text { isolates } \\
(n=50)\end{array}$} & \multicolumn{3}{|c|}{ No. of INH-resistant isolates with indicated INH MIC range $(\mu \mathrm{g} / \mathrm{ml})$} \\
\hline & & & $\begin{array}{c}0.2 \leq \mathrm{MIC}<1 \\
(n=24)\end{array}$ & $\begin{array}{c}1 \leq \mathrm{MIC}<10 \\
(n=48)\end{array}$ & $\begin{array}{c}\text { MIC } \geq 10 \\
(n=15)\end{array}$ \\
\hline furA & Ser5 & 0 & 0 & 1 & 1 \\
\hline \multirow[t]{8}{*}{ kat $G$} & Completed deletion & 0 & 0 & 0 & 2 \\
\hline & Frameshift & 0 & 0 & 1 & 2 \\
\hline & Trp90Stop & 0 & 0 & 1 & 0 \\
\hline & Ser315 & 0 & 9 & 38 & 9 \\
\hline & $\operatorname{Arg} 463$ & 0 & 11 & 17 & 7 \\
\hline & Gly491 & 0 & 0 & 2 & 0 \\
\hline & Arg515 & 0 & 0 & 1 & 0 \\
\hline & Gly685 & 0 & 0 & 1 & 0 \\
\hline \multirow[t]{2}{*}{ inhA promoter } & $-15 \mathrm{C} \rightarrow \mathrm{T}$ & 0 & 2 & 8 & 2 \\
\hline & $-17 \mathrm{G} \rightarrow \mathrm{T}$ & 0 & 0 & 0 & 1 \\
\hline \multirow[t]{2}{*}{$\operatorname{inh} A$} & Ile21 & 0 & 0 & 1 & 1 \\
\hline & Ile 258 & 0 & 0 & 2 & 0 \\
\hline \multirow[t]{6}{*}{ oxyR-ahpC } & $-9 \mathrm{G} \rightarrow \mathrm{A}$ & 0 & 0 & 1 & 1 \\
\hline & $-10 \mathrm{C} \rightarrow \mathrm{T}$ & 0 & 0 & 1 & 0 \\
\hline & $-12 \mathrm{C} \rightarrow \mathrm{T}$ & 0 & 0 & 0 & 2 \\
\hline & $-15 \mathrm{C} \rightarrow \mathrm{T}$ & 0 & 0 & 1 & 0 \\
\hline & $-39 \mathrm{C} \rightarrow \mathrm{T}$ & 0 & 0 & 1 & 3 \\
\hline & $-48 \mathrm{G} \rightarrow \mathrm{A}$ & 0 & 0 & 0 & 1 \\
\hline \multirow[t]{5}{*}{ kas $A$} & Met77 & 0 & 0 & 0 & 1 \\
\hline & Leu245 & 0 & 0 & 1 & 0 \\
\hline & Gly269 & 0 & 1 & 0 & 1 \\
\hline & Gly312 & 8 & 2 & 3 & 1 \\
\hline & Ser341 & 2 & 2 & 0 & 1 \\
\hline \multirow[t]{3}{*}{ Rv0340 } & Thr143 & 4 & 1 & 1 & 0 \\
\hline & Gly149 & 5 & 0 & 0 & 0 \\
\hline & Val163 & 0 & 0 & 1 & 0 \\
\hline \multirow[t]{2}{*}{ iniB } & Frameshift & 0 & 1 & 1 & 0 \\
\hline & Gly192 & 2 & 2 & 1 & 1 \\
\hline \multirow[t]{2}{*}{ iniA } & Arg537 & 0 & 1 & 0 & 1 \\
\hline & His481 & 3 & 2 & 1 & 1 \\
\hline iniC & Frameshift & 0 & 0 & 1 & 1 \\
\hline \multirow[t]{2}{*}{ efp $A$} & Ile73 & 4 & 3 & 2 & 1 \\
\hline & Glu520 & 0 & 0 & 0 & 1 \\
\hline
\end{tabular}

resistance-associated mutation within furA at codon 5 $(\mathrm{Ser} \rightarrow$ Pro $[\mathrm{TCC} \rightarrow \mathrm{CCC}])$ was found in two isolates $(2.3 \%)$. One of the isolates had additional mutations in $k a t G$, the $\operatorname{inh} A$ promoter, and the $\operatorname{oxy} R \rightarrow a h p C$ intergenic region, whereas the other had an additional mutation in the inh $A$ regulatory region. No resistance-associated mutation was detected in the promoter region of fur $A$.

Analysis of the $5^{\prime}$ end of a presumed ribosome binding site in the promoter of $m a b A$-inh $A$ revealed nucleotide substitutions at $-15(\mathrm{C} \rightarrow \mathrm{T} ; n=12[13.8 \%])$ and at $-17(\mathrm{G} \rightarrow \mathrm{T} ; n=$ $1[1.1 \%])$. Of these 13 mutants, two $(15.4 \%)$ isolates had a mutation only in the inh $A$ regulatory region, and one $(7.7 \%)$ isolate had an additional mutation in fur $A$, whereas $10(76.9 \%)$ had additional mutations in $k a t G$ (Table 2). The inh $A$ structure region mutations occurred in four $(4.6 \%)$ isolates among the 87 INH-resistant $M$. tuberculosis strains. Two of these harbored a substitution mutation at codon $258($ Ile $\rightarrow$ Thr $[$ ATC $\rightarrow$ ACC $]$ ), and another two isolates had mutations at codon 21 (Ile $\rightarrow \mathrm{Thr}$ [ATC $\rightarrow$ ACC], $n=1$; Ile $\rightarrow$ Val [ATC $\rightarrow$ GTC], $n=1)$. All four isolates had additional mutations in $\mathrm{katG}$.

Nucleotide substitutions in the oxyR-ahpC intergenic region were found in $10(11.5 \%)$ resistant isolates. All 10 isolates had additional mutations in $\mathrm{katG}$. One isolate had double mutations $(-12 \mathrm{C} \rightarrow \mathrm{T}$ plus $-39 \mathrm{C} \rightarrow \mathrm{T})$ in the $\operatorname{ahp} C$ promoter region, and this isolate had additional mutations in efp $A$ and $k a t G$. Of the 10 isolates with mutations in the $\operatorname{oxy} R$-ahpC intergenic region and $k a t G, 1$ had an additional mutation in fur $A, 1$ in the $i n i B A C$ region, and 1 in $e f p A$. There was no drug-associated mutation detected in the structural region of $a h p C$.

Sequence analysis of the $\operatorname{kas} A$ showed that four (4.6\%) isolates had substitution mutations. Two of these isolates had a missense mutation at codon $269(\mathrm{Gly} \rightarrow \mathrm{Ser}$ [GGT $\rightarrow$ AGT]), one at codon $245(\mathrm{Leu} \rightarrow \mathrm{Arg}$ [CTG $\rightarrow \mathrm{CGG}])$, and one at codon $77(\mathrm{Met} \rightarrow$ Ile $[\mathrm{ATG} \rightarrow$ ATC]). All four isolates had additional 
TABLE 3. INH-resistant M. tuberculosis isolates with mutations in two or more genes

\begin{tabular}{|c|c|c|c|c|c|c|c|c|c|c|c|c|}
\hline \multirow{2}{*}{$\begin{array}{r}\text { No. of } \\
\text { isolates }\end{array}$} & \multirow{2}{*}{$\begin{array}{c}\text { MIC } \\
\text { range } \\
(\mu \mathrm{g} / \mathrm{ml})\end{array}$} & \multicolumn{11}{|c|}{ Mutation(s) ${ }^{a}$} \\
\hline & & furA & $k a t G$ & $\begin{array}{c}\text { inhA } \\
\text { promoter }\end{array}$ & inhA & $o x y R-a h p C$ & kas $A$ & Rv0340 & iniB & iniA & iniC & efp $A$ \\
\hline 1 & 4 & & $1559 \mathrm{C} \mathrm{Del}^{b, e}$ & & & $-15 \mathrm{C} \rightarrow \mathrm{T}$ & & & & & & \\
\hline 1 & 16 & & $1311 \mathrm{~T} \mathrm{Ins}^{c}$ & & & & M771 & & & & & \\
\hline 1 & 32 & & Del & & & $-9 \mathrm{G} \rightarrow \mathrm{A}$ & & & & & & \\
\hline 1 & $>256$ & & Del & & & $-12 \mathrm{C} \rightarrow \mathrm{T}$ & & & & & & \\
\hline 5 & $0.5-32$ & & S315T & $-15 \mathrm{C} \rightarrow \mathrm{T}$ & & & & & & & & \\
\hline 1 & 1 & & S315T & & $\mathrm{I} 21 \mathrm{~T}$ & & & & $198 \mathrm{~T} \mathrm{Ins}^{e}$ & & & \\
\hline 1 & 2 & & S315T & & & $-9 \mathrm{G} \rightarrow \mathrm{A}$ & & & & & & \\
\hline 1 & 2 & & S315T & & & $-39 \mathrm{C} \rightarrow \mathrm{T}$ & & & & & & \\
\hline 1 & 2 & & S315T & & & & & & & & $79 \mathrm{~T}$ Ins & \\
\hline 1 & 16 & & S315T & $-17 \mathrm{G} \rightarrow \mathrm{T}$ & & & & & & & & \\
\hline 1 & 16 & & S315T & & $\mathrm{I} 21 \mathrm{~V}$ & & & & & & & \\
\hline 1 & 16 & & S315T & & & & G269S & & & & $98 \mathrm{~A} \mathrm{Ins}^{e}$ & \\
\hline 1 & 0.5 & & $\mathrm{R} 463 \mathrm{~L}$ & & & & & & & & & \\
\hline 1 & 1 & & R463L & & & & L245R & & & & & \\
\hline 1 & 2 & & R463L & & $\mathrm{I} 258 \mathrm{~T}^{e}$ & & G269S & & & $\mathrm{R} 537 \mathrm{H}$ & & \\
\hline 1 & 4 & & $\mathrm{R} 463 \mathrm{~L}$ & & & & & V1631 & & & & \\
\hline 1 & 16 & & $\mathrm{R} 463 \mathrm{~L}$ & $-15 \mathrm{C} \rightarrow \mathrm{T}$ & & & & & & & & \\
\hline 1 & 16 & S5P & $\mathrm{R} 463 \mathrm{~L}$ & $-39 \mathrm{C} \rightarrow \mathrm{T}^{e}$ & & $-39 \mathrm{C} \rightarrow \mathrm{T}$ & & & & & & \\
\hline 2 & $1-2$ & & S315T; R463L & $-15 \mathrm{C} \rightarrow \mathrm{T}$ & & & & & & & & \\
\hline 1 & 2 & & S315T; R463L & & & $-10 \mathrm{C} \rightarrow \mathrm{T}$ & & & & & & \\
\hline 1 & 32 & & S315T; R463L & & & $-48 \mathrm{G} \rightarrow \mathrm{A}$ & & & & $\mathrm{R} 537 \mathrm{H}$ & & \\
\hline 1 & 64 & & $\begin{array}{l}\text { S315T; } 1329 \text { A } \\
\text { Ins }\end{array}$ & & & $-39 \mathrm{C} \rightarrow \mathrm{T}$ & & & & & & \\
\hline 1 & $>256$ & & $\begin{array}{l}\mathrm{R} 463 \mathrm{~L} ; 1559 \text { Ins of } \\
\quad 64 \mathrm{bp}^{d, e}\end{array}$ & & & $\begin{array}{l}-12 \mathrm{C} \rightarrow \mathrm{T} \\
-39 \mathrm{C} \rightarrow \mathrm{T}\end{array}$ & & & & & & $\mathrm{E} 520 \mathrm{~V}^{e}$ \\
\hline 1 & 4 & & R463L; G491C & & $\mathrm{I}_{258 \mathrm{~T}^{e}}$ & & & & & & & \\
\hline 1 & 2 & S5P & & $-15 \mathrm{C} \rightarrow \mathrm{T}$ & & & & & & & & \\
\hline
\end{tabular}

${ }^{a}$ Amino acid abbreviations: S, Ser; T, Thr; R, Arg; L, Leu; P, Pro; G, Gly; C, Cys; I, Ile; V, Val; M, Met; H, His; E, Glu. Nucleotide abbreviations: A, adenine; C, cytosine; $\mathrm{G}$, guanine, $\mathrm{T}$, thymidine.

${ }^{b}$ Deletion (Del) of nucleotide $\mathrm{C}$ at position 1559.

${ }^{c}$ Insertion (Ins) of nucleotide $\mathrm{T}$ at position 1311.

${ }^{d}$ Insertion (64 bp) at position 1559.

${ }^{e}$ Novel mutation.

mutations in $k a t G$, and two isolates had additional mutations in the iniBAC region as well as in katG. Polymorphisms at codon Gly321 and Ser341 were found in both INH-resistant and -susceptible isolates (Table 2).

The ini region has four genes designated Rv0340, iniB, iniA, and ini $C$; of these genes, iniB, ini $A$, and iniC are organized as an operon. The Rv0340 gene is located upstream of the iniBAC operon and is transcribed in the same orientation $(2,3,8,31)$. Sequence analysis showed that the four genes had mutations associated with drug resistance, and there were seven $(8.0 \%)$ isolates that harbored mutations in this region. One isolate had a mutation at codon 163 of $\mathrm{Rv0340} \mathrm{(Val} \rightarrow$ Ile [GTT $\rightarrow$ ATT]), and this isolate harbored an additional mutation in $k a t G$. Two isolates had insertion (insertion of $\mathrm{T}$ at nucleotide 198) and deletion (deletion of $\mathrm{A}$ at nucleotide 211) mutations in iniB, respectively. Of the two ini $B$ mutants, the insertion mutant harbored additional mutations in $k a t G$ and $\operatorname{inh} A$, in contrast to the deletion mutant, which had no additional mutations at the other loci. Two isolates had a substitution mutation at codon 537 of $\operatorname{ini} A(\mathrm{Arg} \rightarrow \mathrm{His}$ [CGC $\rightarrow \mathrm{CAC}])$. Of the two ini $A$ mutants, one harbored additional mutations in $\mathrm{kat} G$ and the $o x y R$ $\operatorname{ahpC}$ intergenic region, whereas the other had additional mutations in $k a t G$, inh $A$, and $\operatorname{kas} A$. Frameshifts occurred in two ini $C$ mutants, with insertion of $\mathrm{A}$ and $\mathrm{T}$ at nucleotide positions 98 and 79, respectively. The two iniC mutation isolates harbored an additional katG 315 mutation. efp $A$, which encodes an efflux protein, was induced by INH (31). Sequence analysis showed one isolate had a drug resistance-associated mutation at codon $520 \quad(\mathrm{Glu} \rightarrow \mathrm{Val}$ $[\mathrm{GAG} \rightarrow \mathrm{GTG}])$. This isolate had an additional mutation in the oxyR-ahpC intergenic region and double mutations in katG.

\section{DISCUSSION}

All of the 87 INH-resistant isolates from China had mutations in the nine structural genes (furA, katG, inhA, kasA, $\mathrm{Rv} 0340$, iniB, ini $A$, ini $C$, and $e f p A$ ) or two regulatory regions (the $\operatorname{oxyR}$ - $a h p C$ intergenic region and the promoter of $m a b A$ inh $A$ ). Thirty-nine distinct mutations were identified. Among these, mutations in the $k a t G$ gene were predominant, as expected; $k a t G$ mutations were found in $82(94.3 \%)$ isolates. Geographical differences in the frequencies of the $k a t G$ codon 315 mutations were apparent in the analysis of data from other studies: mutations in $\mathrm{kat} G$ codon 315 were detected in only $34.6 \%$ of the INH-resistant isolates from Madrid (18) but were detected in a substantial $93.6 \%$ of isolates from northwest Russia (26). Therefore, the documented information regarding the frequencies and types of mutations in one country or geographical region may not apply generally to other regions. We found mutations in katG codon 315 in $64.4 \%$ of the INHresistant isolates from five provinces of China, which is different from the data (51\%) from Hong Kong (22). Previous work 
found these mutations in 34.6 to $62.2 \%$ of INH-resistant isolates, for which MICs of INH were at least $0.2 \mu \mathrm{g} / \mathrm{ml}(12,27$, 35), whereas other investigators found these mutations in 61.9 to $97.4 \%$ of INH-resistant isolates, for which MICs of INH were at least $1 \mu \mathrm{g} / \mathrm{ml}(6,1,17,24)$. These findings suggest that mutations in the kat $G$ codon 315 are associated with high levels of INH resistance. This was also observed in our study (Table $2)$. Of the 24 isolates exhibiting low levels of INH resistance $(0.2 \mu \mathrm{g} / \mathrm{ml} \leq \mathrm{MIC}<1 \mu \mathrm{g} / \mathrm{ml}), 9(37.5 \%)$ isolates showed this mutation. In contrast, $38(79.2 \%)$ and $9(60 \%)$ isolates showing intermediate $(1 \mu \mathrm{g} / \mathrm{ml} \leq \mathrm{MIC}<10 \mu \mathrm{g} / \mathrm{ml})$ and high $(\mathrm{MIC} \geq$ $10 \mu \mathrm{g} / \mathrm{ml}$ ) levels of INH resistance harbored the $\mathrm{kat} G$ codon 315 mutation, respectively.

Previous findings indicated that $k a t G$ codon 463 was a polymorphic site and that the $k a t G$ codon 463 mutation (Arg $\rightarrow$ Leu) was not associated with INH resistance $(14,22,36)$. In our study, no mutation at codon 463 of $\mathrm{kat} G$ was detected in 50 INH-susceptible isolates with different IS6110 fingerprints, but 35 (40.2\% of the 87 INH-resistant M. tuberculosis isolates) INH-resistant isolates had a mutation at codon 463 of $k a t G$. Among the 35 Arg463Leu mutants, 11 (31.4\%) $(0.2 \mu \mathrm{g} / \mathrm{ml} \leq$ $\mathrm{MIC}<0.5 \mu \mathrm{g} / \mathrm{ml})$ isolates had no additional mutations at other loci. A total of $24(68.6 \%)$ (MIC $\geq 1 \mu \mathrm{g} / \mathrm{ml})$ isolates harbored additional mutations at katG or other genes. The $k a t G$ Arg463Leu mutation was associated with low levels of INH resistance among the clinical isolates from eastern China.

Double point mutations in two separate loci of kat $G$ were detected in 20 isolates from China, with substitutions at codons 315 and 463 being predominant (Table 1). Regardless of the mutations in other genes, four $(12.5 \%)$ isolates of the $32 \mathrm{~kat} G$ mutants harboring the single mutation of Ser315Thr exhibited high levels of INH resistance ( $\mathrm{MIC} \geq 10 \mu \mathrm{g} / \mathrm{ml}$ ). And three $(17.6 \%)$ isolates of the $17 \mathrm{~kat} G$ mutants harboring the single mutation of Arg463Leu exhibited high levels of INH resistance. Of the 13 isolates harboring double mutations of Ser315Thr and Arg463Leu in katG, 3 (23.1\%) isolates exhibited high levels of INH resistance. Piatek et al. suggest that isolates develop resistance to INH by a stepwise accumulation of mutations, which may be important for achieving the higher levels of resistance or maintaining virulence in a human host (27). In our study, the association between high levels of INH resistance and the accumulation of mutations in katG supports such a hypothesis. However, this hypothesis does not exclude the possibility that full resistance can also develop in a single step, as has been observed in laboratory mutants. This possibility will be explored in future studies.

Five novel mutations within $\mathrm{kat} G$ were found in this investigation. They were mutations Gly $\rightarrow$ Cys $($ GGC $\rightarrow$ TGC) at codon 491, Arg $\rightarrow$ Tyr $(\mathrm{CGC} \rightarrow$ TAC) at codon 515, and $\mathrm{Gly} \rightarrow \operatorname{Arg}(\mathrm{GGC} \rightarrow \mathrm{CGC})$ at codon 685 , deletion of $\mathrm{G}$ at position 1559, and a 64-bp fragment insertion at position 1559. The 64-bp nucleic acid came from duplication of a fragment of $k a t G$ (from positions 1496 to 1559), and this insertion mutation did not create a frameshift or termination mutation in katG. The isolate harboring the 64-bp fragment insertion had additional mutations in the $\operatorname{xxy} R-a h p C$ intergenic region and $\operatorname{efp} A$. The additional mutation in $e f p A$ was $\mathrm{Glu} \rightarrow \mathrm{Val}(\mathrm{GAG} \rightarrow \mathrm{GTG})$ at codon 520 , which has not been previously described. Ramaswamy et al. reported that efp $A$ had no INH resistanceassociated mutation (31). Additional studies of INH-resistant
M. tuberculosis isolates from global populations are needed to see whether the mutation in this gene plays a role in INH resistance.

Previous studies indicate that mutations in the upstream region of $\operatorname{inh} A$ result in an increase of InhA expression, thereby elevating the drug target levels and producing INH resistance via a titration mechanism (29). Previous investigators found inhA promoter mutations in 10 to $34.2 \%$ of the INH-resistant isolates $(18,12,17,20,35)$. In the current study, the mutations in the promoter region of $i n h A$ were found in $14.9 \%$ of the INH-resistant isolates from China. A novel substitution mutation at position $-17(\mathrm{G} \rightarrow \mathrm{T})$ was observed. The mutations identified in the structural region of inhA result in INH resistance due to the reduced binding affinity of the INH$\mathrm{NAD}^{+}$adduct for enoyl reductase (35). Our results suggest that the substitution frequency $(4.6 \%)$ of $i n h A$ was very low. Two isolates harbored a novel substitution mutation at codon 258 (Ile $\rightarrow$ Thr).

Mutations in the oxyR-ahpC region occurred in $10(11.5 \%)$ isolates. One isolate harbored double mutations $(-12 \mathrm{C} \rightarrow \mathrm{T}$ plus $-39 \mathrm{C} \rightarrow \mathrm{T}$ ) in this region, and they have not been described previously. Previous reports found mutations of the oxyR-ahpC region in 4.8 to $24.2 \%$ of the INH-resistant isolates $(6,16,21)$. In our study, all 10 isolates had an additional mutation in $k a t G$, and the MICs were higher than $2 \mu \mathrm{g} / \mathrm{ml}$. Genetic and biochemical studies have shown that certain mutations of the $a h p C$ promoter region result in overexpression of $a h p C$ as a compensatory mechanism for the loss of catalase activity due to kat $G$ mutations $(16,38)$.

The iniBAC operon encodes genes that are induced by a broad range of antibiotics, including INH and ethambutol (3). Mutations in the ini genes were identified in INH-resistant $M$. tuberculosis isolates as well as in ethambutol-resistant isolates $(30,31)$. One isolate harbored a frameshift mutation with an insertion of $\mathrm{T}$ at nucleotide position 198 in iniB. One isolate had an insertion of $\mathrm{A}$ at 98 in iniC. These results have not been previously discovered.

Analysis of the nine structural genes (furA, $\mathrm{kat} G, \operatorname{inh} A, \mathrm{kas} A$,

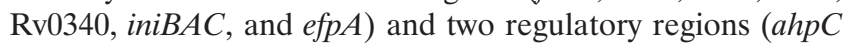
and inh $A$ ) of $87 \mathrm{M}$. tuberculosis clinical isolates from China was performed, and a variety of mutations were identified. The present findings contribute substantially to our knowledge of the spectrum of gene mutations that may participate in INH resistance and provide clues for elucidating the drug-resistance mechanisms of $M$. tuberculosis. Rapid detection of the $M$. tuberculosis complex is critical to enable the appropriate antimycobacterial therapy for patients to commence promptly as well as to control the spread of this pathogen. Therefore, more information regarding these mutations would be beneficial for the development of novel molecular diagnostic methods such as the DNA line probe and DNA microarrays $(39,40)$.

\section{ACKNOWLEDGMENTS}

This work was supported by National Basic Research Program (2002CB512804) and the National Natural Science Foundation (30270072), China.

\section{REFERENCES}

1. Abate, G., S. E. Hoffner, V. O. Thomsen, and H. Miorner. 2001. Characterization of isoniazid-resistant strains of Mycobacterium tuberculosis on the basis of phenotypic properties and mutations in katG. Eur. J. Clin. Microbiol. Infect. Dis. 20:329-333. 
2. Alland, D., I. Kramnik, T. T. Weisbrod, L. Otsubo, R. Cerny, L. P. Miller, W. R. Jacobs, Jr., and B. R. Bloom. 1998. Identification of differentially expressed mRNA in prokaryotic organisms by customized amplification libraries (DECAL): the effect of isoniazid on gene expression in Mycobacterium tuberculosis. Proc. Natl. Acad. Sci. USA 95:13227-13232.

3. Alland, D., A. J. Steyn, T. Weisbrod, K. Aldrich, and W. R. Jacobs, Jr. 2000 Characterization of the Mycobacterium tuberculosis iniBAC promoter, a promoter that responds to cell wall biosynthesis inhibition. J. Bacteriol. 182: 1802-1811.

4. Bardou, F., C. Raynaud, C. Ramos, M. A. Laneele, and G. Laneele. 1998 Mechanism of isoniazid uptake in Mycobacterium tuberculosis. Microbiology 144:2539-2544.

5. Becerra, M. C., J. Bayona, J. Freeman, P. E. Farmer, and J. Y. Kim. 2000 Redefining MDR-TB transmission-drug resistance "hot spots." Int. J. Tuber. Lung Dis. 4:387-394.

6. Cardoso, R. F., R. C. Cooksey, G. P. Morlock, P. Barco, L. Cecon, F. Forestiero, C. Q. F. Leite, D. N. Sato, M. de Lourdes Shikama, E. M. Mamizuka, R. D. C. Hirata, and M. H. Hirata. 2004. Screening and characterization of mutations in isoniazid-resistant Mycobacterium tuberculosis isolates obtained in Brazil. Antimicrob. Agents Chemother. 48:3373-3381.

7. Cavusoglu, C., S. Himioglu, S. Guneri, and A. Bilgic. 2002. Characterization of $r p o B$ mutations in rifampin-resistant clinical isolates of Mycobacterium tuberculosis from Turkey by DNA sequencing and line probe assay. J. Clin. Microbiol. 40:4435-4438.

8. Cole, S. T., R. Brosch, J. Parkhill, T. Garnier, C. Churcher, D. Harris, S. V. Gordon, K. Eiglmeier, S. Gas, C. E. Barry III, F. Tekaia, K. Badcock, D. Basham, D. Brown, T. Chillingworth, R. Connor, R. Davies, K. Devlin, T. Feltwell, S. Gentles, N. Hamlin, S. Holroyd, T. Hornsby, K. Jagels, A. Krogh, J. McLean, S. Moule, L. Murphy, K. Oliver, J. Osborne, M. A. Quail, M.-A Rajandream, J. Rogers, S. Rutter, K. Seeger, J. Skelton, R. Squares, S. Squares, J. E. Sulston, K. Taylor, S. Whitehead, and B. G. Barrell. 1998 Deciphering the biology of Mycobacterium tuberculosis from the complete genome sequence. Nature 393:537-544.

9. Dye, C., S. Scheele, P. Dolin, V. Pathania, and M. C. Raviglione. 1999 Consensus statement. Global burden of tuberculosis: estimated incidence, prevalence, and mortality by country. WHO Global Surveillance and Monitoring Project. JAMA 282:677-686.

10. Dye, C., B. G. Williams, M. A. Espinal, and M. C. Raviglione. 2002. Erasing the world's slow stain: strategies to beat multidrug-resistant tuberculosis. Science 295:2042-2046.

11. Espinal, M. A., A. Laszlo, L. Simonsen, F. Boulahbal, S. J. Kim, A. Reniero, S. Hoffner, H. L. Rieder, N. Binkin, C. Dye, R. Williams, and M. C. Raviglione. 2001. Global trends in resistance to antituberculosis drugs. N. Engl. J. Med. 344:1294-1303.

12. Gonzalez, N., M. J. Torres, J. Aznar, and J. C. Palomares. 1999. Molecular analysis of rifampin and isoniazid resistance of Mycobacterium tuberculosis clinical isolates in Seville, Spain. Tuber. Lung Dis. 79:187-190.

13. Herrera, L., S. Jiménez, A. Valverde, M. A. García-Aranda, and J. A. SáezNieto. 2003. Molecular analysis of rifampin-resistant Mycobacterium tuberculosis isolated in Spain (1996-2001). Description of new mutations in the rpoB gene and review of the literature. Int. J. Antimicrob. Agents 21:403408.

14. Herrera, L., A. Valverde, P. Saiz, J. A. Sáez-Nieto, J. L. Portero, and M Soledad Jiménez. 2004. Molecular characterization of isoniazid-resistant Mycobacterium tuberculosis clinical strains isolated in the Philippines. Int. J. Antimicrob. Agents 23:572-576.

15. Herrera-León, L., T. Molina, P. Saíz, J. A. Sáez-Nieto, and M. Soledad Jiménez. 2005. New multiplex PCR for rapid detection of isoniazid-resistan Mycobacterium tuberculosis clinical isolates. Antimicrob. Agents Chemother. 49:144-147.

16. Kelley, C. L., D. A. Rouse, and S. L. Morris. 1997. Analysis of $a h p C$ gene mutations in isoniazid-resistant clinical isolates of Mycobacterium tuberculosis. Antimicrob. Agents Chemother. 41:2057-2058.

17. Kiepiela, P., K. S. Bishop, A. N. Smith, L. Roux, and D. F. York. 2000 Genomic mutations in the $k a t G, \operatorname{inh} A$ and $a h p C$ genes are useful for the prediction of isoniazid resistance in Mycobacterium tuberculosis isolates from Kwazulu Natal, South Africa. Tuber. Lung Dis. 80:47-56.

18. Kim, S.-Y., Y.-J. Park, W.-I. Kim, S.-H. Lee, C. L. Chang, S.-J. Kang, and C.-S. Kang. 2003. Molecular analysis of isoniazid resistance in Mycobacterium tuberculosis isolates recovered from South Korea. Diagn. Microbiol. Infect. Dis. 47:497-502.

19. Kremer, K., B. K. Y. Au, P. C. W. Yip, R. Skuce, P. Supply, K. M. Kam, and D. van Soolingen. 2005. Use of variable-number tandem-repeat typing to differentiate Mycobacterium tuberculosis Beijing family isolates from Hon Kong and comparison with IS6110 restriction fragment length polymorphism typing and spoligotyping. J. Clin. Microbiol. 43:314-320.

20. Lee, A. S., I. H. Lim, L. L. Tang, A. Telenti, and S. Y. Wong. 1999. Contribution of kas A analysis to detection of isoniazid-resistant Mycobacterium tuberculosis in Singapore. Antimicrob. Agents Chemother. 43:2087-2089.

21. Lee, A. S. G., A. S. M. Teo, and S.-Y. Wong. 2001. Novel mutations in $n d h$ in isoniazid-resistant Mycobacterium tuberculosis isolates. Antimicrob. Agents Chemother. 45:2157-2159.
22. Leung, E. T. Y., K. M. Kam, A. Chiu, P. L. Ho, W. H. Seto, K. Y. Yuen, and W. C. Yam. 2003. Detection of katG Ser315Thr substitution in respiratory specimens from patients with isoniazid-resistant Mycobacterium tuberculosis using PCR-RFLP. J. Med. Microbiol. 52:999-1003.

23. Marrakchi, H., G. Laneelle, and A. Quemard. 2000. InhA, a target of the antituberculosis drug isoniazid, is involved in a mycobacterial fatty acid elongation system, Fas-II. Microbiology 146:289-296.

24. Marttila, H. J., H. Soini, E. Eerola, E. Vyshnevskaya, B. I. Vyshnevskiy, T. F. Otten, A. V. Vasilyef, and M. K. Viljanen. 1998. A Ser315Thr substitution in $\mathrm{kat} G$ is predominant in genetically heterogeneous multidrug-resistant $\mathrm{Myco}$ bacterium tuberculosis isolates originating from the St. Petersburg area in Russia. Antimicrob. Agents Chemother. 42:2443-2445.

25. Mdluli, K., R. A. Slayden, Y. Zhu, S. Ramaswamy, X. Pan, D. Mead, D. D. Crane, J. M. Musser, and C. E. Barry III. 1998. Inhibition of a Mycobacterium tuberculosis $\beta$-ketoacyl ACP synthase by isoniazid. Science 280:16071610.

26. Mokrousov, I., O. Narvskaya, T. Otten, E. Limeschenko, L. Steklova, and B. Vyshnevskiy. 2002. High prevalence of KatG Ser315Thr substitution among isoniazid-resistant Mycobacterium tuberculosis clinical isolates from northwestern Russia, 1996 to 2001. Antimicrob. Agents Chemother. 46:14171424.

27. Piatek, A. S., A. Telenti, M. R. Murray, H. El-Hajj, W. R. Jacobs, Jr., F. R. Kramer, and D. Alland. 2000. Genotypic analysis of Mycobacterium tuberculosis in two distinct populations using molecular beacons: implications for rapid susceptibility testing. Antimicrob. Agents Chemother. 44:103-110.

28. Pym, A. S., P. Domenech, N. Honoré, J. Song, V. Deretic, and S. T. Cole. 2001. Regulation of catalase-peroxidase (KatG) expression, isoniazid sensitivity and virulence by furA of Mycobacterium tuberculosis. Mol. Microbiol. 40:879-889.

29. Ramaswamy, S., and J. M. Musser. 1998. Molecular genetic basis of antimicrobial agent resistance in Mycobacterium tuberculosis: update. Tuber. Lung Dis. 79:3-29.

30. Ramaswamy, S. V., A. G. Amin, S. Goksel, C. E. Stager, S. J. Dou, H. El Sahly, S. L. Moghazeh, B. N. Kreiswirth, and J. M. Musser. 2000. Molecular genetic analysis of nucleotide polymorphisms associated with ethambutol resistance in human isolates of Mycobacterium tuberculosis. Antimicrob. Agents Chemother. 44:326-336.

31. Ramaswamy, S. V., R. Reich, S. J. Dou, L. Jasperse, X. Pan, A. Wanger, T. Quitugua, and E. A. Graviss. 2003. Single nucleotide polymorphisms in genes associated with isoniazid resistance in Mycobacterium tuberculosis. Antimicrob. Agents Chemother. 47:1241-1250.

32. Rozwarski, D. A., G. A. Grant, D. H. R. Barton, W. R. Jacobs, and J. C. Sacchettini. 1998. Modification of the NADH of the isoniazid target (inhA) from Mycobacterium tuberculosis. Science 279:98-102.

33. Sacchettini, J. C., and J. S. Blanchard. 1996. The structure and function of the isoniazid target in Mycobacterium tuberculosis. Res. Microbiol. 147:3643.

34. Smith, K. C., L. Armitige, and A. Wanger. 2003. A review of tuberculosis reflections on the past, present and future of a global epidemic disease. Expert. Rev. Anti. Infect. Ther. 1:483-491.

35. Telenti, A., N. Honore, C. Bernasconi, J. March, A. Ortega, B. Heym, H. Takiff, and S. T. Cole. 1997. Genotypic assessment of isoniazid and rifampin resistance in Mycobacterium tuberculosis: a blind study at reference laboratory level. J. Clin. Microbiol. 35:719-723.

36. van Doorn, H. R., E. J. Kuijper, A. van der Ende, A. G. A. Welten, D. van Soolingen, P. E. W. de Haas, and J. Dankert. 2001. The Susceptibility of Mycobacterium tuberculosis to isoniazid and the $\mathrm{Arg} \rightarrow$ Leu mutation at codon 463 of kat $G$ are not associated. J. Clin. Microbiol. 39:1591-1594.

37. van Embden, J. D., M. D. Cave, J. T. Crawford, J. W. Dale, K. D. Eisenach, and B. Gicquel. 1993. Strain identification of Mycobacterium tuberculosis by DNA fingerprinting: recommendations for standardized methodology J. Clin. Microbiol. 31:406-409.

38. Wilson, T., G. W. Lisle, J. A. Marcinkeviciene, J. S. Blanchard, and D. M. Collins. 1998. Antisense RNA to $a h p C$, an oxidative stress defense gene involved in isoniazid resistance, indicates that $\mathrm{AhpC}$ of Mycobacterium bovis has virulence properties. Microbiology 144:2687-2695.

39. Woods, G. L. 2002. The mycobacteriology laboratory and new diagnostic techniques. Infect. Dis. Clin. N. Am. 16:127-144.

40. Woods, G. L., J. S. Bergmann, and N. Williams-Bouyer. 2001. Clinical evaluation of the Gen-Probe Amplified Mycobacterium Tuberculosis Direct Test for rapid detection of Mycobacterium tuberculosis in select nonrespiratory specimens. J. Clin. Microbiol. 39:747-749

41. World Health Organization. 2005. Global tuberculosis control: surveillance, planning, financing (WHO/HTM/TB/2005.349). World Health Organization, Geneva, Switzerland.

42. Yue, J., W. Shi, J. Xie, Y. Li, E. Zeng, and H. Wang. 2003. Mutation in the $r p o B$ gene of multidrug-resistant Mycobacterium tuberculosis isolates from China. J. Clin. Microbiol. 41:2209-2212.

43. Zahrt, T. C., J. Song, J. Siple, and V. Deretic. 2001. Mycobacterial FurA is a negative regulator of catalase-peroxidase gene katG. Mol. Microbiol. 39: 1174-1185. 